\title{
SHAKEDOWN OF A CT SPECIMEN WITH St52 STEEL-EXPERIMENTAL, ANALYTICAL AND NUMERICAL INVESTIGATIONS
}

\author{
Y. J. HUANG Institut für Baumechanik und Numerische Mechanik, University of Hannover, Germany* \\ E. STEIN Institut fiir Baumechanik und Numerische Mechanik, University of Hannover, Germany
}

\begin{abstract}
The paper deals with the shakedown behaviour of a CT (compact tension) specimen consisting of St52 steel under cyclical loading. Experiments have been carried out for determining the shakedown limit load. For comparison, the analytical and numerical methods are used to study the same problem. Satisfactory agreement has been achieved between the results from these different methods.
\end{abstract}

Key words: cyclical loading, shakedown behaviour, plastic deformation, kinematic hardening

\section{INTRODUCTION}

An elastic-plastic system subjected to cyclical loadings may behave in a very complicated manner. Frederick and Armstrong (1) $\dagger$ pointed out that the stresses and increments of plastic strains in the system will become stationary after a certain number of loading cycles. The system shakes down, it fails due to alternating plasticity (low cycle fatigue) or it fails incrementally (ratcheting).

By shakedown, a system reaches a state in which no further plastic deformations occur although loadings can still vary. Shakedown is regarded as a safe state of a system. As early as in 1938, Melan $(2,3)$ formulated static shakedown theorems for elastic-perfectly plastic materials as well as for linear, unlimited kinematic hardening materials. Koiter (4) introduced a kinematic shakedown theorem for a perfectly plastic material, a dual one of Melan's static theorem. A shakedown theorem for materials with non-linear hardening has been formulated for the first time by Neal (5), who used a Masing overlay model (6) to describe the non-linear kinematic hardening behaviour of materials. Neal's formulation is only valid for one-dimensional stress state problems. Recently, Stein and co-workers (7-9) used a three-dimensional overlay model to describe the non-linear kinematic hardening behaviour of ductile materials and formulated a corresponding shakedown theorem for this material model. Following this method, the failure mechanism of a system under cyclical loading can be determined. For instance, a system consisting of linear kinematic hardening material fails only locally by alternating plasticity (see reference (9)).

An important task of shakedown investigations is to find the maximum extension of the given load domain, within which the system will still shake down. In the

\footnotetext{
The MS. of this paper was received at the Institution on 4 July 1994 and accepted for publication on 7 February 1995

* Corresponding author: Institut für Baumechonik und Numerische Mechanik, Universität Hannover, Appelstrasse 9A, D-30167 Hannover, Germany

$\dagger$ References are given in the Appendix
}

framework of computational mechanics, this kind of optimization problem can be solved by using the finite element method (FEM). Generally, the dimension of the optimization problem is very large; Mahnken (10) and Zhang (11) used special numerical methods, namely the dual method and the reduced base technique, to solve these problems. For linear kinematic hardening materials, however, Stein and Huang (12) developed an analytical method to determine the shakedown limit load.

There are only a few experimental investigations on shakedown. Most of the published experiments are done for simple structures. König (13) reported and commented on most results in this context. In this paper the experimental results obtained for CT specimens consisting of St52 steel are reported. At the same time, the problem is treated by using analytical and numerical methods. Results of these different methods will be compared and discussed. The reason why a CT specimen was chosen for experiments is that the result of a notched CT specimen is useful for the prediction of the fatigue threshold of a cracked body (see reference (14)).

\subsection{Notation}

$\mathscr{I}$ Set of Gaussian points

$\mathscr{J}$ Set of vertices in the load domain

$K_{\mathrm{I}} \quad$ Stress intensity factor

$m$ Safety factor against inadaptation

$N \quad$ Number of loading cycles

$N_{\mathrm{e}} \quad$ Number of finite elements

$N_{\mathrm{g}} \quad$ Number of Gaussian points of an element

$N_{s} \quad$ Number of stress components of a Gaussian point

$P \quad$ Applied load

$P^{\mathrm{e}} \quad$ Elastic limit load

$P^{\text {sl }} \quad$ Shakedown limit load with linear kinematic hardening material

$P^{\text {sn }} \quad$ Shakedown limit load with non-linear kinematic hardening material 
$P^{\text {sp }} \quad$ Shakedown limit load with elastic-perfectly plastic material

$P^{u} \quad$ Ultimate load

$r \quad$ Notch radius

$\bar{\alpha}(\boldsymbol{x}) \quad$ Back stress field

$\beta \quad$ Shakedown load factor

$\varepsilon \quad$ Strain

$\overline{\boldsymbol{p}}(\boldsymbol{x})$ Eigen stress field

$\sigma \quad$ Stress

$\sigma_{\text {eff }} \quad$ Effective stress

$\sigma^{\mathbf{E}} \quad$ Elastic stress field

$\sigma_{v} \quad$ Ultimate stress

$\sigma_{0} \quad$ Initial yield stress

$\Phi$ Yield function

\section{SHAKEDOWN EXPERIMENTS WITH CT SPECIMEN}

A CT specimen with a notch is illustrated in Fig. 1, which has been used very frequently for fracture experiments. The specimen consists of St52 steel. The chemical composition of this material is given in Table 1.

The $\sigma-\varepsilon$ diagram of this material under a monotonic load is shown in Fig. 2. It has an initial yield stress of $\sigma_{0}=35.5 \mathrm{kN} / \mathrm{cm}^{2}$. After yielding, the material behaves at first as if it were perfectly plastic. Up to $\varepsilon=1.2$ per cent, the $\sigma-\varepsilon$ curve approaches a straight line in a hardening manner. A more detailed description of mechanical behaviour of this material can be found in reference (15).

For investigating the shakedown behaviour of CT specimens, loadings with different amplitudes $P$ and different numbers of loading cycles $N$ have been used. Eleven strain gauges have been bonded to a specimen. Thus, the strain distribution along the notch ligament can be measured. This information can be used for identification of material parameters (16). Locations of strain gauges are shown in Fig. 3. One of them is located

Table 1. Chemical composition of St 52 steel

\begin{tabular}{ccccccc}
\hline $\mathrm{C}$ & $\mathrm{Si}$ & $\mathrm{Mn}$ & $\mathrm{P}$ & $\mathrm{S}$ & $\mathrm{Al}$ & $\mathrm{N}_{2}$ \\
\hline 0.096 & 0.291 & 1.390 & 0.015 & 0.006 & 0.041 & 0.010 \\
\hline
\end{tabular}

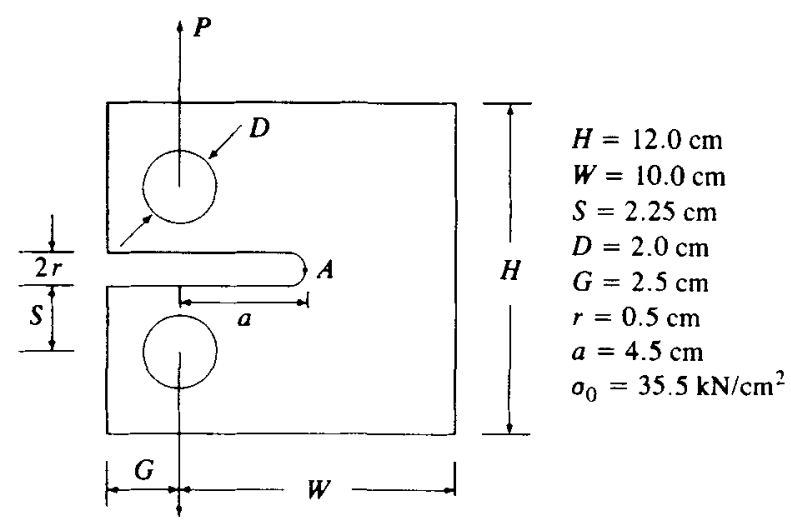

Fig. 1. A compact tension specimen

directly at the notch root (point A). Theoretically, the information at this point is most important. Therefore, the strain there should be measured. Technically, however, it is difficult to do. On the one hand, the deformation at point A may be large, while on the other hand the strain gauge at point $\mathrm{A}$ is curved and responds in an unstable fashion as loading proceeds. In some experiments the strain gauge comes off the specimen after a number of loading cycles. Therefore, the measurements at this point are not reliable. The information obtained from strain gauges 1 to 10 (see Fig. 3) are used to determine the shakedown limit load. Experiments show that once the shakedown is measured by strain gauge 1 , the shakedown condition will also be satisfied by other strain gauges. This indicates that among these ten strain gauges, the information of strain gauge 1 is most important for the shakedown investigation. In this work, therefore, only some of the important results obtained from strain gauge 1 will be shown. For readers who are interested in knowing the whole experiments, details can be found in reference (15). Furthermore, for the sake of simple notation, the point where strain gauge 1 is located will be denoted by $B$, which is at a distance of $2 \mathrm{~mm}$ from point $\mathrm{A}$.

In all the experiments, steady states for loading-

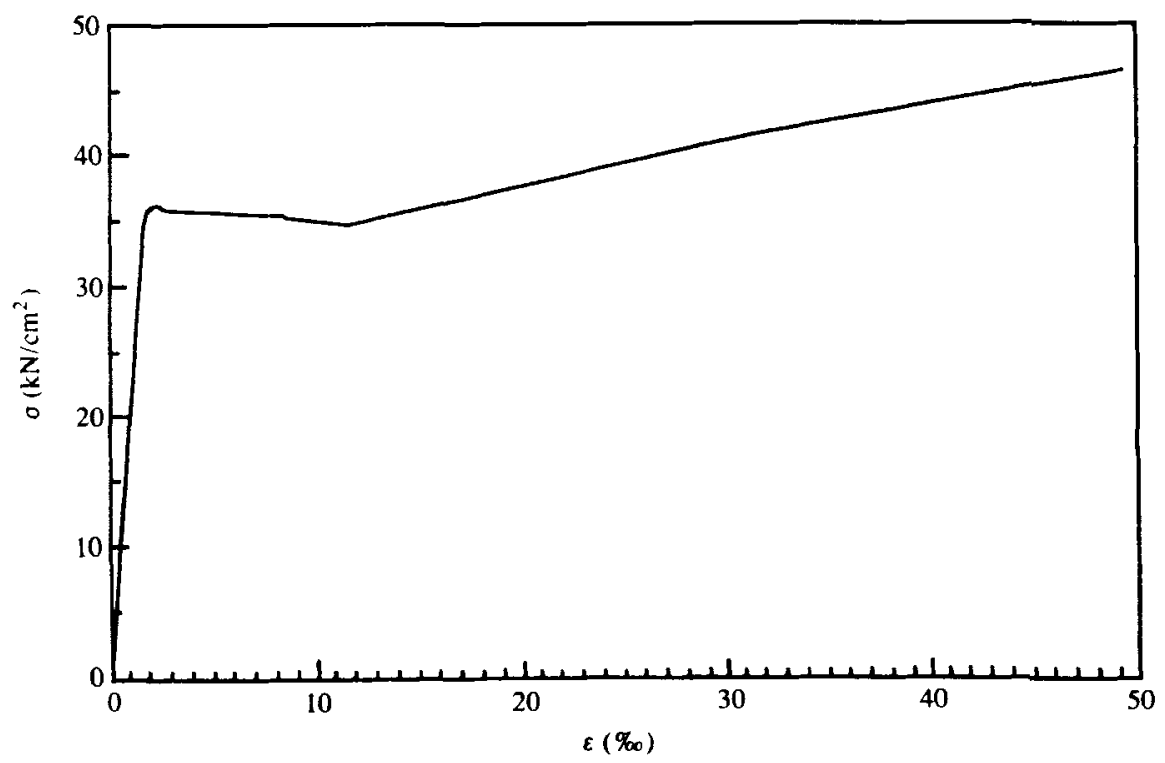

Fig. 2. $\sigma-\varepsilon$ diagram of $S 152$ steel 
Front side

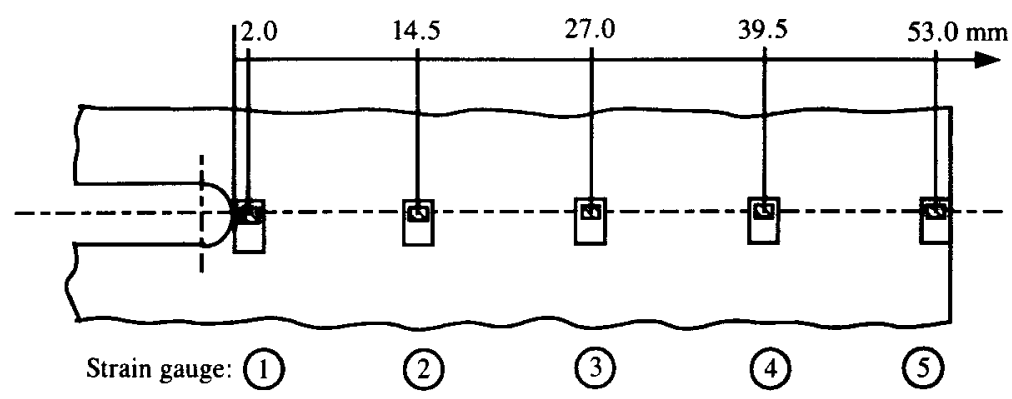

Back side



Fig. 3. Locations of strain wire gauges on the specimen

deformation relations are reached after $c a .10$ loading cycles. This verifies the theory of Frederick and Armstrong (1). There are three different types of steady states. The first one is shakedown, as shown in Figs 4(a) and $5(a)$, in which no plastic deformation occurs after the steady state is reached and the system responds as if it were elastic. The second one is alternating plasticity (also called plastic shakedown), as shown in Fig. 4(b), (c) and (d), in which the plastic deformation increment from one loading cycle to another is zero. However, within one cycle, the first half of the loading-deformation path (the loading path) is not identical with the second one (the unloading path) and during such a cycle the plastic energy is dissipated. In this case, the system can fail in a form of low cycle fatigue. The third steady state is ratcheting, as shown in Figs 5(b) and 6. In the ratcheting state, the plastic deformation grows from one cycle to another and after a larger number of cycles the system deforms so much that it becomes unserviceable.

Before starting the shakedown experiments, the elastic limit load $P^{\mathrm{e}}$ of the CT specimen is established by a test experiment with a monotonically increasing loading. It is found that $P^{\mathrm{e}}=8.8 \mathrm{kN}$.

In the first experiment, four loadings with different amplitudes $(0 \rightleftharpoons 8.75 \mathrm{kN}, 0 \rightleftharpoons 17.0 \mathrm{kN}, 0 \rightleftharpoons 17.75 \mathrm{kN}$ and $0 \rightleftharpoons 18.5 \mathrm{kN})$ and different cycles $(10,30,30$ and 30$)$ are applied. The loading-deformation diagrams of point $B$ are presented in Fig. 4. It can be seen that for the loading of $P=8.75 \mathrm{kN}$ the system shakes down, while for loadings of $P=17.0 \mathrm{kN}, P=17.75 \mathrm{kN}$ and $P=18.5 \mathrm{kN}$ the system does not shake down. This means that the shakedown limit load of the $\mathrm{CT}$ specimen lies between $P=8.75 \mathrm{kN}$ and $P=17.0 \mathrm{kN}$.

In the second experiment, two different loadings $(P=15.0 \mathrm{kN}$ and $P=18.0 \mathrm{kN})$ with $N=2000$ are applied. The loading-deformation diagrams of point $\mathrm{B}$ are given in Fig. 5. For the loading of $P=15.0 \mathrm{kN}$ the system shakes down, while for the loading of $P=18.0$ $\mathrm{kN}$ the system does not shake down.
For the third experiment, loading amplitudes are $P=18.0 \mathrm{kN}$ and $P=20.0 \mathrm{kN}$ with $N$ equal to 2000 . The loading-deformation diagrams of point $B$ are drawn in Fig. 6. It can be seen that for both of these loadings the system does not shake down.

For the fourth experiment, loadings of $P=12.0 \mathrm{kN}$, $P=20.0 \mathrm{kN}$ and $P=25.0 \mathrm{kN}$ with $N=500$ are used. From the loading-deformation diagrams it is obvious that for $P=12.0 \mathrm{kN}$ the system shakes down, while for loadings of $P=20.0 \mathrm{kN}$ and $P=25.0 \mathrm{kN}$ the system does not shake down.

By the fifth experiment, a loading with amplitude $P=35.0 \mathrm{kN}$ is repeated until the specimen fails. It has been observed that for $N=4950$ a crack of length 2.5 $\mathrm{mm}$ at the notch root has been developed, while for $N=6950$ the CT specimen breaks down totally.

Comparing all the experimental results, it can be concluded that the shakedown limit load of the system measured at point $\mathrm{B}$ is between $P=15.0 \mathrm{kN}$ and $P=17.0$ $\mathrm{kN}$. In order to obtain a more accurate result, further experiments with loading amplitudes between 15.0 and $17.0 \mathrm{kN}$ must be done.

It is obvious that point $A$, not point $B$, dominates the shakedown behaviour of the CT specimen. The elastic stress at $\mathrm{A}$ is higher than the one at $\mathrm{B}$; consequently the correct shakedown limit load of the CT specimen should be smaller than that measured from point $\mathrm{B}$. It is therefore reasonable to take $P=15.0 \mathrm{kN}$ rather than $P=17.0 \mathrm{kN}$ as the shakedown limit load of the CT specimen.

\section{ANALYTICAL AND NUMERICAL APPROACHES}

In this section, first some shakedown theorems are briefly reviewed. The formulations and mathematical proofs of these theorems can be found in references (2), (3), (7) and (11). The shakedown problem investigated experimentally in the last section is treated again analytically and numerically with the help of these theorems. 
Y. J. HUANG AND E. STEIN



(a) Test 01 load $P=8.75 \mathrm{kN}$, cycles $n=10$, wire strain gauge 01



(b) Test 01 load $P=17 \mathrm{kN}$, cycles $n=30$, wire strain gauge 01

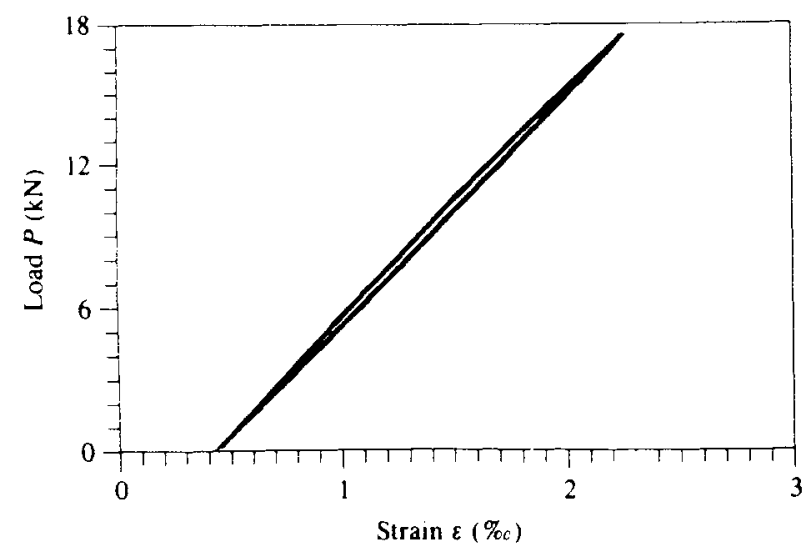

(c) Test 01 load $P=17.75 \mathrm{kN}$, cycles $n=30$, wire strain gauge 01



(d) Test 01 load $P=18.5 \mathrm{kN}$, cycles $n=30$, wire strain gauge 01

Fig. 4. Load-strain diagrams at B for experiment 1

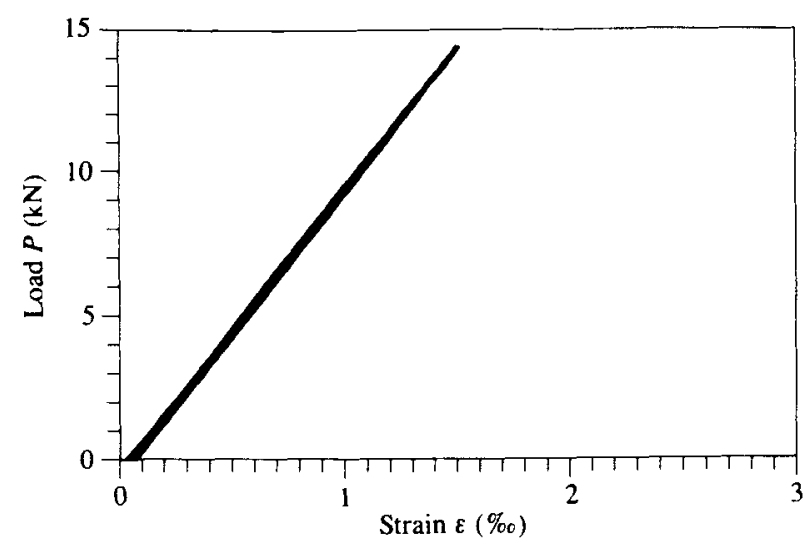

(a) Test 02 load $P=15.0 \mathrm{kN}$, cycles $n=2000$, wire strain gauge 01

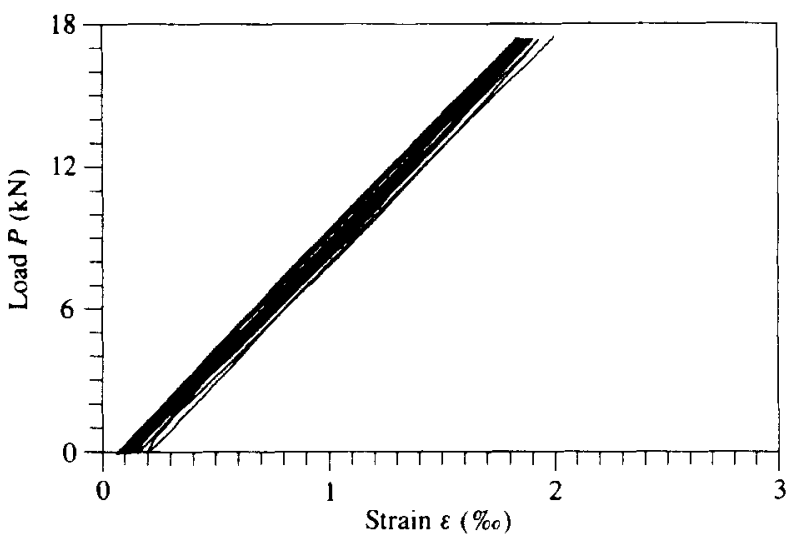

(b) Test 02 load $P=18.0 \mathrm{kN}$, cycles $n=2000$, wire strain gauge 01

Fig. 5. Load-strain diagrams at $B$ for experiment 2

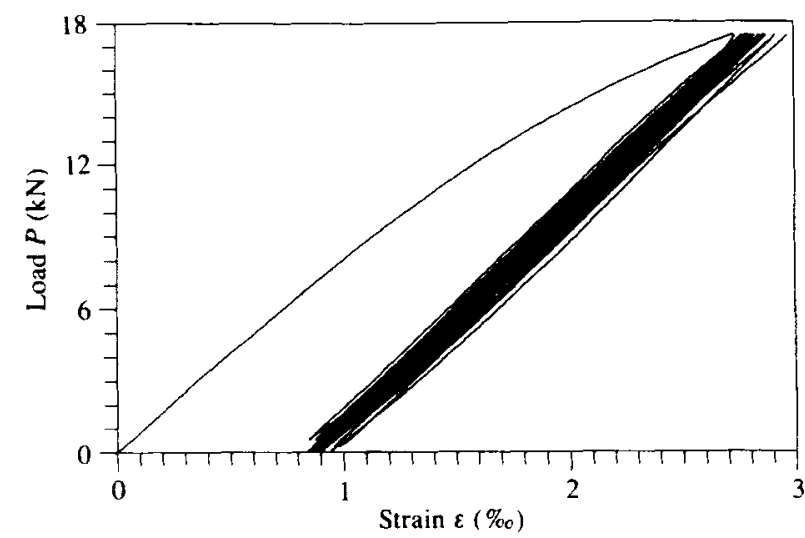

(a) Test $03 \operatorname{load} F=18.0 \mathrm{kN}$, cycles $n=2000$, wire strain gauge 01

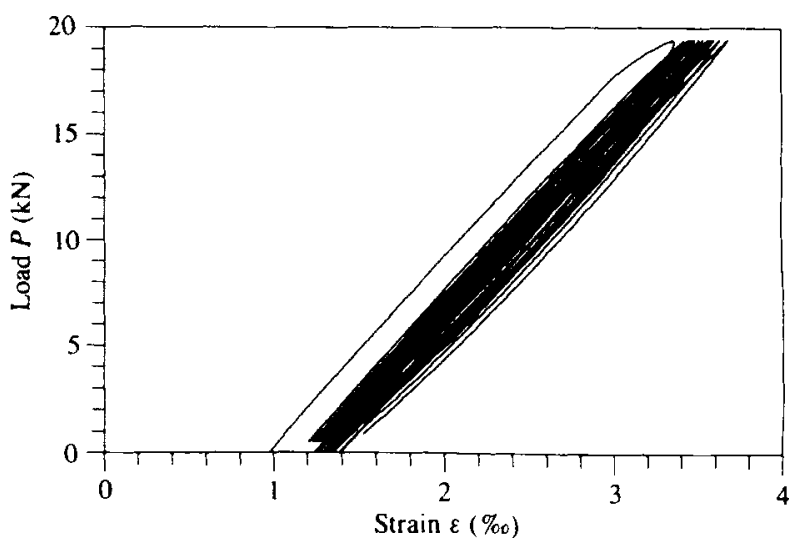

(b) Test $03 \operatorname{load} F=20.0 \mathrm{kN}$, cycles $n=2000$, wire strain gauge 01

Fig. 6. Load-strain diagrams at $B$ for experiment 3 


\section{Theorem I}

For systems consisting of elastic-perfectly plastic material, if a time-independent eigen stress field $\bar{\rho}(\boldsymbol{x})$ exists such that for all possible loads within a given load domain the condition

$$
\boldsymbol{\Phi}\left[m\left\{\boldsymbol{\sigma}^{\mathrm{E}}(\boldsymbol{x}, t)+\overline{\boldsymbol{\rho}}(\boldsymbol{x})\right\}\right] \leqslant \sigma_{0}^{2}(\boldsymbol{x})
$$

is fulfilled $\forall \boldsymbol{x} \in \Omega$ and $\forall t>0$, where $m>1$ is a safety factor against inadaptation, then the total plastic energy dissipated within an arbitrary load path contained within the load domain is bounded and the system will shake down.

\section{Theorem 2}

For systems consisting of linear kinematic hardening material, if a time-independent eigen stress field $\bar{\rho}(\boldsymbol{x})$ and a time-independent back stress field $\bar{\alpha}(x)$ exist such that for all possible loads within a given load domain the condition

$$
\boldsymbol{\Phi}\left[m\left\{\boldsymbol{\sigma}^{\mathrm{E}}(\boldsymbol{x}, t)+\overline{\boldsymbol{\rho}}(\boldsymbol{x})-\overline{\boldsymbol{\alpha}}(\boldsymbol{x})\right\}\right] \leqslant \sigma_{0}^{2}(\boldsymbol{x})
$$

is fulfilled $\forall x \in \Omega$ and $\forall t>0$, then the system will shake down.

\section{Theorem 3}

For systems consisting of non-linear kinematic hardening material, if a time-independent eigen stress field $\overline{\boldsymbol{\rho}}(\boldsymbol{x})$ and a time-independent field $\bar{\alpha}(\boldsymbol{x})$ exist satisfying

$$
\boldsymbol{\Phi}\{m \bar{\alpha}(x)\} \leqslant\left\{\sigma_{u}(x)-\sigma_{0}(x)\right\}^{2} \quad \forall x \in \Omega
$$

such that for all possible loads within the load domain the condition

$$
\Phi\left[m\left\{\boldsymbol{\sigma}^{\mathrm{E}}(\boldsymbol{x}, t)+\overline{\boldsymbol{\rho}}(\boldsymbol{x})-\bar{\alpha}(x)\right\}\right] \leqslant \sigma_{0}^{2}(\boldsymbol{x})
$$

is fulfilled $\forall x \in \Omega$ and $\forall t>0$, then the system will shake down.

In Theorems 1 to $3, \Phi$ is the yield function, $\sigma^{\mathrm{E}}$ the elastic stress field, $\sigma_{0}$ the initial yield stress and $\sigma_{u}$ the ultimate stress of the material. Note that Theorems 1 and 2 can be obtained from Theorem 3 by replacing $\sigma_{u}$ with $\sigma_{0}$ and with $\infty$. In Theorem $1 \bar{\alpha}=0$, in Theorem 2 the back stress $\bar{\alpha}$ is an unlimited quantity, whereas in Theorem $3 \bar{\alpha}$ must fulfil condition (3).

If the elastic limit load of a system is denoted by $P^{\mathrm{e}}$, its ultimate load by $P^{u}$, the shakedown limit load of the system with elastic-perfectly plastic material by $P^{\text {sp }}$, the shakedown limit load of the system with linear kinematic hardening material by $P^{\text {sl }}$ and the shakedown limit load of the same system with non-linear kinematic hardening material by $P^{\mathrm{sn}}$, then the following relation holds :

$$
P^{\mathrm{e}} \leqslant P^{\mathrm{sp}} \leqslant P^{\mathrm{sn}} \leqslant P^{\mathrm{sl}} \leqslant P^{\mathrm{u}}
$$

The notch stress analysis of the CT specimen gives an elastic limit load of $P^{\mathrm{e}}=8.44 \mathrm{kN}$, which is 4 per cent less than the one obtained from experiment.

For a system consisting of linear kinematical material, Stein and Huang (12) developed an analytical method for determining the shakedown limit load. Following this method, the shakedown limit load of a CT specimen is found to be

$$
P^{s l}=P \frac{2 \sigma_{0}}{\sigma_{\text {eff }}}
$$

where $P$ is the applied load (see Fig. 1) and $\sigma_{\text {eff }}$ the maximum effective stress in the $C T$ specimen. It is obvious that the maximum effective stress will appear at the notch root. By assuming that the CT specimen has a plane stress state, then $\sigma_{\text {eff }}$ equals the principal elastic stress at point $\mathrm{A}$ (denoted by $\sigma_{\mathrm{A}}$ ) in the direct perpendicular to the notch ligament, because other stress components in this point are zero.

It should be noted that result (6) is only applicable for special cases in which materials are linear kinematical hardening and the load domain has only one parameter. For more general cases, results can be found in reference (12). The problem now is that St52 steel is not a linear hardening material, as can be seen from Fig. 2. Consequently, the analytical result (6) cannot be simply applied to the CT specimen. Here a statement made in a previous paper must be recalled. It was stated that the kinematic hardening does not influence the shakedown limit load, that is

$$
P^{\text {sp }}=P^{\text {sn }}=P^{\text {sl }}
$$

when the system would fail locally. It is obvious that a CT specimen is of local character. Therefore, result (6) can be use for this problem. Let $\sigma_{\text {eff }}$ equal $\sigma_{\mathrm{A}}$; then equation (6) becomes

$$
P^{\text {sl }}=P \frac{2 \sigma_{0}}{\sigma_{\mathrm{A}}}
$$

In the determination of $P^{s 1}$, the stress $\sigma_{\mathrm{A}}$ is required. Usually, stresses at a point in a complicated system should be calculated by using a numerical method such as FEM or BEM (boundary element method). In this work, however, an analytical form suggested by Paris and $\mathrm{Sih}(17)$ has been employed:

$$
\sigma_{\mathrm{A}}=\frac{2 K_{\mathrm{I}}}{\sqrt{ }(\pi r)}
$$

where $K_{1}$ is the stress intensity factor obtained from fracture mechanics as if the notch were a crack and $r$ is the notch root radius. For a CT specimen the $K_{1}$ factor can be expressed as

$$
\begin{aligned}
K_{\mathrm{I}}= & \frac{P}{B W^{1 / 2}}\left\{29.6\left(\frac{a}{W}\right)^{1 / 2}-185.5\left(\frac{a}{W}\right)^{3 / 2}\right. \\
& \left.+655.7\left(\frac{a}{W}\right)^{5 / 2}-1017\left(\frac{a}{W}\right)^{7 / 2}+638.9\left(\frac{a}{W}\right)^{9 / 2}\right\}
\end{aligned}
$$

where $B$ stands for the thickness of the specimen and meanings for other symbols are given in Fig. 1. Substituting all these quantities into equation (10) and then into equation (9) and letting $P=1.0 \mathrm{kN}$ gives $\sigma_{\mathrm{A}}=4.21$ $\mathrm{kN} / \mathrm{cm}^{2}$. According to equation (8), the shakedown limit load of the CT specimen is $P^{s 1}=16.87 \mathrm{kN}$. Using equations (9) and (10), the elastic limit load of the CT specimen is calculated; it has a value $P^{\mathrm{e}}=8.44 \mathrm{kN}$. The shakedown limit load $P^{\text {sl }}$ is just twice as large as its elastic limit load $\boldsymbol{P}^{\mathbf{c}}$.

The same problem has been calculated using a finite element method. On account of symmetry, half of the CT specimen is divided into 894 elements. Due to a strong stress concentration at the notch root, the FE mesh 




Fig. 7. Adaptive FE mesh of half a CT specimen

shown in Fig. 7 is generated adaptively, using asymptotic a posteriori indicators and quantitative errors (see reference (18)).

As mentioned above, the kinematic hardening has no influence on the shakedown limit load in this case. Thus the shakedown theorem 1 can be used. The optimization is then formulated as

$$
\begin{aligned}
& \beta \rightarrow \max \\
& \boldsymbol{\Phi}\left[\beta\left\{\boldsymbol{\sigma}^{\mathrm{E}}(\boldsymbol{x}, j)+\boldsymbol{\rho}(\boldsymbol{x})\right\}\right] \leqslant \sigma_{0}^{2}, \quad x \in \Omega, j \in \mathscr{I}
\end{aligned}
$$

where $\Omega$ is the body and $\mathscr{g}$ the set of all vertices in the load domain. For this problem $\Omega$ is the CT specimen and $g=2$.

Dividing the system into $N_{\mathrm{e}}$ elements with $N_{\mathrm{g}}$ Gaussian points in each element gives the following discretized optimization problem:

$$
\begin{aligned}
& \beta \rightarrow \max \\
& \sum_{i=1}^{N_{\mathrm{e}} \times N_{\mathrm{g}}} \mathbf{C}_{i} \cdot \boldsymbol{\rho}_{i}=\mathbf{C} \cdot \boldsymbol{\rho}=\mathbf{0} \\
& \boldsymbol{\Phi}\left(\beta \boldsymbol{\sigma}_{i}^{\mathrm{E}}(j)+\boldsymbol{\rho}_{i}\right) \leqslant \sigma_{0}^{2} \quad \forall(i, j) \in \mathscr{I} \times \mathscr{J}
\end{aligned}
$$

where $\mathscr{I}=\left[1,2, \ldots, N_{\mathrm{e}} \times N_{\mathrm{g}}\right], \mathrm{C}$ a system dependent matrix and $\boldsymbol{\sigma}_{i}^{E}(j)$ the elastic stress vector at the ith Gaussian point due to the $j$ th load vertex.

Depending on $\Phi$, the problem (12) to (14) may be linear or non-linear. In this work, the von Mises yield function is used. Thus, a non-linear optimization problem must be solved. In general, the discretized problem (12) to (14) is a large-sized optimization problem. Let $N_{\mathrm{S}}$ be the number of stress components in a Gaussian point, with unknowns for the problem (12) to (14) equal to $N_{\mathrm{S}} \times N_{\mathrm{e}} \times N_{\mathrm{g}}+1$. For our problem, $N_{\mathrm{s}}=$ $3, N_{\mathrm{e}}=894$ and $N_{\mathrm{g}}=4$; the unknowns are then 10729 . A direct application of standard optimization algorithms, such as the sequential quadratic programming (SQP) method (see reference (19)), is not effective. A socalled reduced basis technique developed by Stein and co-workers has been used. This method has been proved to be very effective for solving shakedown problems. Details of this method can be found in references $(9)$ and (11).

The finite element computation gives the following results:
1. The elastic limit load $P^{\mathrm{e}}=8.4 \mathrm{kN}$.

2. The shakedown limit load $P^{\mathrm{s}}=16.8 \mathrm{kN}$.

The difference between the numerical and analytical shakedown limit loads is less than 1 per cent.

\section{CONCLUDING REMARKS}

In this paper, the shakedown behaviour of CT specimens consisting of St52 steel subjected to cyclical loadings is investigated by using experimental, analytical and numerical methods. It is shown that loading levels exist between the elastic limit load and ultimate load of the system, for example $P=12.0 \mathrm{kN}$ and $P=15.0 \mathrm{kN}$, under which the system shakes down. The maximum value of these loadings, called the shakedown limit load, is determined. Depending on the different methods, the shakedown limit load is found to be $15.0 \mathrm{kN}$ (experimental), $16.88 \mathrm{kN}$ (analytical) and $16.80 \mathrm{kN}$ (numerical) respectively. The results of analytical and numerical approaches are in good agreement. The experimental result is about 10 per cent less than those from other methods. This disagreement is probably due to the fact that in the shakedown theorems, based on which analytical and numerical approaches are formulated, simple material modes are used, while factors such as creep, softening and damage, which can influence shakedown behaviour of a system, are not considered.

\section{APPENDIX}

\section{REFERENCES}

(1) FREDERICK, C. O. and ARMSTRONG, P. J. 'Convergent internal stresses and steady cyclic states of stress', J. Strain Analysis, 1966, 1(2), 154-159.

(2) MELAN, E. 'Der Spannungszustand eines Mises-Henckyschen Kontinuums bei veränderlicher Belastung', Sitzher. Akad. Wiss. Wien, 1938, 11a, 147, 73-78

(3) MELAN, E. 'Zur Plastizität des räumlichen Kontinuums', Ing.Arch., 1938, 8, 116-126.

(4) KOITER, W. T. 'A new general theorem on shakedown of elasticplastic structures', Proc. Koninkl. Akad. Wet.. 1956, B59, 24-34.

(5) NEAL, B. G. 'Plastic collapse and shakedown theorems for structures of strain-hardening material', J. Aero Sci., 1950, 17, 297-306.

(6) MASING, G. 'Zur Heyn'schen Theorie der Verfestigung der Metalle durch verborgen elastische Spannungen', Wiss. Veröff. aus dem Siemens-Konzern, 1924, 3, 231-239.

(7) STEIN. E., ZHANG, G. and KÖNIG, J. A. 'Shakedown with nonlinear hardening including structural computation using finite element method', Int. J. Plasticity, 1992, 8, 1-31. 
(8) STEIN, E. and ZHANG, G. 'Theoretical and numerical shakedown analysis for kinematic hardening materials', Proceedings of 3rd Conference on Computational Plasticity, Barcelona, 1992, pp. $1-25$.

(9) STEIN, E., ZHANG, G. and HUANG, Y. 'Modelling and computation of shakedown problems for nonlinear hardening materials', Computer Meth. in Mechanics and Engng, 1993, 103, 247-272.

(10) MAHNKEN, R. Duale Methoden für nichtlineare Optimierungsprobleme in der Strukturmechanik, PhD Thesis, Universität Hannover, 1992.

(11) ZHANG, G. Einspielen und dessen numerische Behandlung von Flächentragwerken aus ideal plastischem bzw. kinematisch verfestigendem Material, $\mathrm{PhD}$ Thesis, Universität Hannover, 1992.

(12) STEIN, E. and HUANG, Y. 'An analytical method to solve shakedown problems with linear kinematic hardening materials', Int. $J$. Solids and Structs, 1994, 31(18), 2433-2444.

(13) KÖNIG, J. A. Shakedown of Elastic-Plastic Structures, 1987 (PWN-Polish Scientific Publisher, Warsaw).

(14) HUANG, Y. J. and STEIN, E. 'Prediction of the fatigue threshold by using shakedown theory', Fatigue and Fracture of Engng Mater. and Structs, 1995, 18(3), 363-370.

(15) REIFENSTEIN, L. Verhalten von modifizierten CT-Proben aus Baustahl St 52 unter zyklischer Belastung im elastisch-plastischen Bereich, Studienarbeit, Technische Universität, Braunschweig. 1993.

(16) MAHNKEN, R. and STEIN, E. 'The identification of parameters for visco-plastic models via finite-element methods and gradient methods', Modelling Simul. Mater. Sci. Engng, 1994, 2, 597-616.

(17) PARIS, P. C. and SIH, G. C. 'Fracture toughness testing and its applications', ASTM STP 381, 1965 (American Society for Testing and Materials, New York), pp. 30-83.

(18) STEIN, E., RUST, W. and OHNIMUS, $S$. ' $h$ - and $d$-Adaptive FE methods for two-dimensional structural problems including postbuckling of shells', Computer Meth. in Mechanics and Engng, 1992, 101, 315-354.

(19) SCHITTOWSKI, K. 'The nonlinear programming method of Wilson, Han and Powell with an augmented Lagrangian type line search function', Numer. Math., 1981, 38, 83-127. 